\title{
Effect of side groups on the properties of cationic
}

\author{
polyaspartamides
}

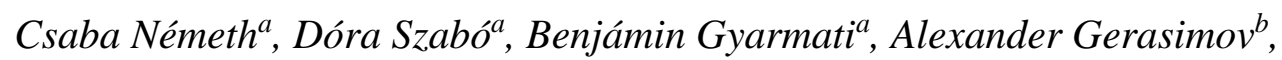 \\ Mikhail Varfolomeev ${ }^{b}$, Timur Abdullinc ${ }^{c}$ Krisztina Lászlóa ${ }^{a}$, András Szilágyia*
}

${ }^{a}$ D epartment of $\mathrm{P}$ hysical $\mathrm{C}$ hemistry and $\mathrm{M}$ aterials Science, Budapest $\mathrm{U}$ niversity of Technology and E conomics, M üegyetem rkp. 3., H-1111 Budapest, H ungary

${ }^{b}$ D epartment of Physical Chemistry, Kazan (Volga Region) F ederal U niversity, 420008

Kazan, Russia

Institute of F undamental M edicine and B iology, Kazan (Volga Region) F ederal U niversity, 18 K remlyovskaya St., 420008 Kazan, Russia

Corresponding author, e-mail: aszilagyi@ mail.bme.hu

\section{GRAPHICAL ABSTRACT}
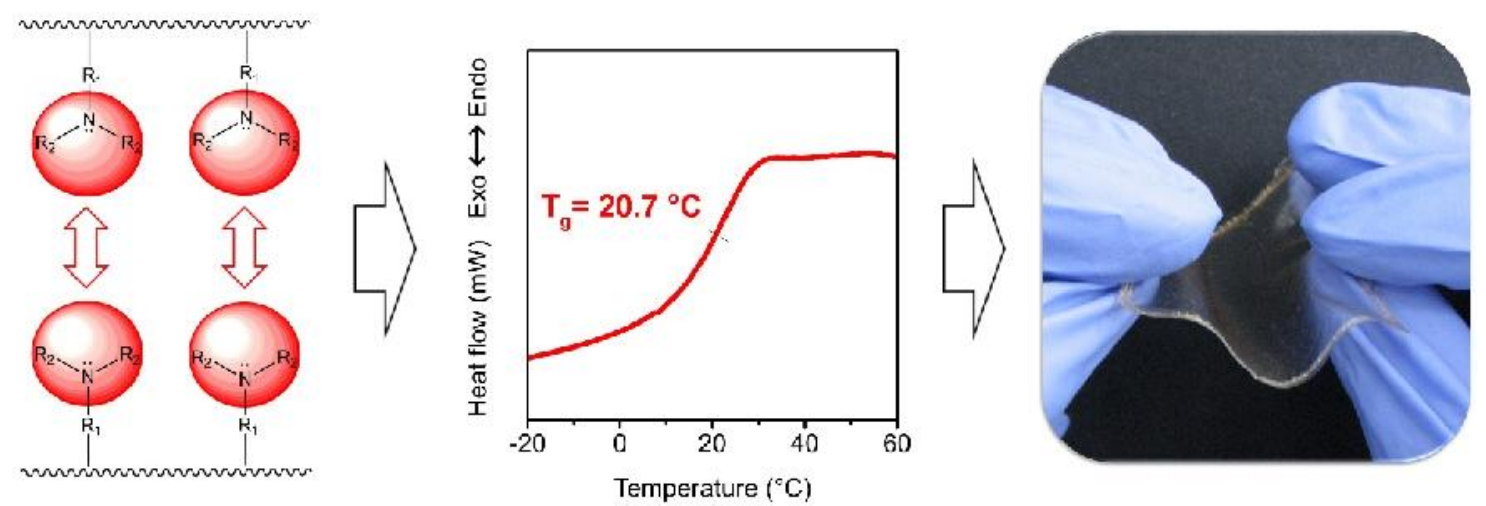


\section{HIGHLIGHTS}

- Polyaspartamides with dialkylaminoalkyl and alkyl side groups were synthesized.

- The polymers have glass transition temperatures around $25^{\circ} \mathrm{C}$ and are thermally stable.

- A correlation was established between the $\mathrm{T}_{\mathrm{g}}$ and the polymer composition.

- Dissolution kinetics of the polymers was determined by fluorescent labeling.

\section{ABSTRACT}

Polyaspartamides with dialkylaminoalkyl and short chain alkyl side groups were synthesized and characterized in order to prepare polymer films. Their structure was confirmed by nuclear magnetic resonance $\left({ }^{1} \mathrm{H}\right.$ NMR) and Fourier transform infrared (FTIR) spectroscopy and their thermal decomposition temperature $\left(\mathrm{T}_{\mathrm{d}}\right)$ was determined by thermogravimetric analysis. The composition of the polymers was adjusted to obtain polyaspartamides with glass transition temperatures $\left(\mathrm{T}_{\mathrm{g}}\right)$ at around room temperature and the relationship between the structure and the properties was examined. The dissolution profile of polymer films made of polyaspartamides was measured with the help of fluorescent marking to show that dissolution rate of the films depends on the $\mathrm{pH}$ and can be controlled by the composition of the polymers.

\section{KEYWORDS}

biopolymers, cationic polyaspartamide, thermal analysis, fluorescent marking, taste masking 


\section{INTRODUCTION}

A large amount of drug molecules have unpleasant taste which makes their oral administration uncomfortable [1,2]. The taste masking of pharmaceuticals used in the GI tract can be achieved with entero-soluble coatings, which have poor or moderate solubility in the mouth, but they are highly soluble at the $\mathrm{pH}$ of the stomach [2,3]. Polymers with tertiary amine side groups are used as starting materials for the coatings, because these side groups provide low solubility at neutral and slightly alkaline $\mathrm{pH}\left(\mathrm{pH}_{\text {saliva }} \sim 7,[4]\right)$, but very high solubility in acidic media $\left(\mathrm{pH}_{\text {stomach }} \sim 1.2\right)$. Furthermore, the tertiary amine side groups act as internal plasticizers resulting in $\mathrm{T}_{\mathrm{g}}$ values below the room temperature which provides large deformability for the film coatings prepared from these polymers $[5,6]$.

The most commonly used polymers in entero-soluble film coatings for taste masking are derivatives of poly(acrylic acid) and poly(methacrylic acid) with dialkylaminoalkyl side groups (cationic polyacrylates), e.g. dimethylaminoethyl(meth)acrylate (Eudragit ${ }^{\circledR}$ E, Eudragit ${ }^{\circledR}$ E PO) [6-8] and diethyaminoethyl(meth)acrylate (Kollicoat ${ }^{\circledR}$ Smartseal 30 D) [2,9]. Solubility, rate of dissolution, decomposition- and glass transition temperature can be controlled by the copolymerization of properly chosen (meth)acrylic esters $[5,10]$. However, acrylate copolymers have several disadvantages, such as moderate adjustment of their physico-chemical properties, and relatively complex synthesis of the monomers and/or the polymers often requiring toxic additives [10,11]. Additionally, polyacrylates are not biodegradable in general [10].

These drawbacks can be overcome by the application of polyaspartamides which can be synthesized with large structural variety under mild reaction conditions because their precursor polymer, polysuccinimide (PSI) exhibits high reactivity towards primary amines [12-15]. Moreover, due to their protein like structure, these polymers are expected to be biocompatible [16] and biodegradable [17]. 
A limited number of publications deal with the synthesis and characterization of cationic polyaspartamides. Polymers $[18,19]$ and gels $[15,20]$ displaying temperature or $\mathrm{pH}$ sensitivity or sol-gel transition [16] were prepared using (di)alkylaminoalkyl - e.g. isopropylaminoethyl or dimethylaminopropyl - ligands as side groups. However, no attempts have been made to determine the effect of side groups on the thermal properties and dissolution rate of these polymers. Moreover, according to the best of our knowledge, polymer films have not been prepared from polyaspartamides up to now.

Accordingly, our aim was to synthesize polyaspartamides with tertiary amine side groups to adjust their glass transition temperature $\left(\mathrm{T}_{\mathrm{g}}\right)$ to around room temperature. PSI was modified with various dialkylaminoalkyl- and alkylamines and the chemical structure of the polymers was confirmed by nuclear magnetic resonance $\left({ }^{1} \mathrm{H}\right.$ NMR) and Fourier transform infrared (FTIR) spectroscopy. Thermogravimetric measurements were carried out to determine the thermal stability of the polymers. Furthermore, we analyzed the relationship between the $\mathrm{T}_{\mathrm{g}}$ and the chemical structure of the polyaspartamides. Polymer films were prepared by solvent evaporation and the dissolution rate of the various polyaspartamides at $\mathrm{pH}=1.2$ and $\mathrm{pH}=6.8$ was characterized by fluorescent tracking.

\section{EXPERIMENTAL}

\subsection{M aterials}

3-(dimethylamino)-1-propylamine $\quad$ (DMP, 99\%), 2-dimethylaminoethylamine (DME, 98\%), 2-diethylaminoethylamine (DEE, 99\%), phosphoric acid (99\%), L-tryptophan methyl ester hydrochloride (T), triethyl citrate (TEC, $298 \%), \mathrm{D}_{2} \mathrm{O}(99.9$ atom\% $\mathrm{D}$, contains $0.05 \mathrm{wt} \%$ 3-(trimethylsilyl)propionic-2,2,3,3-d4 acid, sodium salt (TMS)) and $\mathrm{d}_{6}$-DMSO (99.96 atom\% D, contains 0.03 vol\% tetramethylsilane) were bought from Sigma-Aldrich. L-aspartic acid (99\%), 3-(diethylamino)-1-propylamine (DEP, \29\%), n-propylamine (P, 99\%), dibutylamine (DBA, 99\%), potassium chloride (99.5\%), and dimethyl sulfoxide (DMSO, 
299.9\%) were purchased from Merck. Hydrochloric acid (HCl, 35\%) and ethyl acetate (EtAc, 99.89\%) were obtained from LachNer. N,N-Dimethylformamide (99.9\%), 2-propanol (99.9\%), n-hexylamine $(\mathrm{H}, 99 \%)$ and sodium hydroxide $(\mathrm{NaOH}$, a.r.) were bought from Reanal. All of the reagents and solvents were used without further purification. Ultrapure water was used for all reactions and the preparation of aqueous solutions (Millipore Milli-Q Gradient, $\rho>18.2 \Omega \mathrm{m})$. Gastric fluid was simulated with an $\mathrm{HCl}$ solution $(\mathrm{pH}=1.2)$, while saliva by PBS buffer $(\mathrm{pH}=6.8)$. The ionic strength of the solutions was adjusted to $0.15 \mathrm{M}$ by the addition of $\mathrm{KCl}$. The $\mathrm{pH}$ of the buffer solutions was checked with a $\mathrm{pH} /$ ion analyzer (Radelkis OP 271/1).

\subsection{Synthesis and preparation}

\subsubsection{Synthesis of polysuccinimide}

Polysuccinimide (PSI) was synthesized by the thermal polycondensation of $L$-aspartic acid in a solvent free reaction. $20.00 \mathrm{~g}(0.15 \mathrm{~mol})$ of $\mathrm{L}$-aspartic acid and $20.00 \mathrm{~g}(0.2 \mathrm{~mol})$ of crystalline phosphoric acid were mixed in a rotary flask and the mixture was heated to $200{ }^{\circ} \mathrm{C}$ under vacuum using a rotary evaporator. The pressure was maintained at 10 mbar during the reaction. A slightly brown product was formed after $5 \mathrm{~h}$. PSI was purified by precipitation in DMF- $\mathrm{H}_{2} \mathrm{O}$ (1:3) and dried in vacuum at $25{ }^{\circ} \mathrm{C}$ for $24 \mathrm{~h} .{ }^{1} \mathrm{H}$ NMR (300 MHz, d 6 -DMSO): 5.27 (1H, CO-CH -CH $\left.{ }_{2}-\mathrm{CO}\right) ; 3.21$ and $2.70\left(2 \mathrm{H}, \mathrm{CO}-\mathrm{CH}-\mathrm{CH}_{2}-\mathrm{CO}\right)$.

The viscosity average molecular weight of polysuccinimide $\left(M_{v, P S I}\right)$ was determined by viscometry. PSI was dissolved in $0.1 \mathrm{M} \mathrm{LiCl/DMF}$ solution, and samples with polymer concentration between 0.004 and $0.02 \mathrm{~g} \mathrm{~mL}^{-1}$ were prepared for the measurement. The experiment was carried out using a rolling ball viscometer (Anton Paar Lovis 2000) at a tilting angle of $45^{\circ}$. Diameters of the capillary and the ball used were 1.6 and $1.5 \mathrm{~mm}$, respectively. 
$M_{v, P S I}$ was calculated from the intrinsic viscosity data using the Kuhn-Mark-Houwink equation:

$$
[\eta]=K M \underset{v, P S I}{\alpha}
$$

where $K=1.32 \times 10^{-1}$ and $\alpha=0.76$ for PSI were taken from the literature [21]. $M_{v, P S I}$ was determined to be $29 \mathrm{kDa}$.

Poly(aspartic acid) (PASP) was synthesized by the hydrolysis of PSI. $1 \mathrm{~g}(0.01 \mathrm{~mol})$ of PSI was added to $200 \mathrm{~cm}^{3} 0.1 \mathrm{M} \mathrm{NaOH}_{(\mathrm{aq})}$ and the mixture was stirred for $5 \mathrm{~h}$. The final solution was dialyzed against ultrapure water and lyophilized. A slightly yellow product was obtained. ${ }^{1} \mathrm{H}$ NMR $\left(300 \mathrm{MHz}, \mathrm{D}_{2} \mathrm{O}\right): 4.55$ (1H, NH-CH $\left.-\mathrm{CO}-\mathrm{CH}_{2}\right), 2.66\left(2 \mathrm{H}, \mathrm{CO}-\mathrm{CH}-\mathrm{CH}_{2}-\mathrm{CO}\right)$.

\subsubsection{Synthesis of cationic polyaspartamides}

PSI was functionalized with dialkylaminoalkyl and alkyl side groups by the nucleophilic addition of various dialkylaminoalkyl- and alkylamines onto the imide groups of the polymer chain (Scheme 1). A typical procedure was as follows (e.g. PSI modified with $90 \mathrm{~mol} \%$ 3-(dimethylamino)-1-propylamine and $10 \mathrm{~mol} \%$ propylamine; abbreviated as DMP90P10): $3.00 \mathrm{~g}$ of PSI (30.93 mmol of succinimide repeating units) was dissolved in $26 \mathrm{~g}$ of DMSO and then $2.844 \mathrm{~g}$ of 3 -(diethylamino)-1-propylamine $(27.83 \mathrm{mmol})$ was added dropwise to the solution. The mixture was stirred at room temperature for $24 \mathrm{~h}$. Afterwards, $0.238 \mathrm{~g}$ of n-propylamine (4.02 mmol, in excess) was added to the solution and the mixture was stirred at room temperature for another $24 \mathrm{~h}$. The polymer was precipitated by adding $400 \mathrm{ml}$ of ethyl acetate, the precipitate was filtered and washed four times with $50 \mathrm{ml}$ of ethyl acetate then dried under vacuum at $25^{\circ} \mathrm{C}$ for $24 \mathrm{~h}$. A slightly yellow powder was obtained with an average yield of $75 \%$. The polymers were stored at room temperature.

DMP90P10: ${ }^{1} \mathrm{H}$ NMR (500 MHz, d6-DMSO, $)$ [ppm]: 4.55 (1H, NH-CH -CO-CH 2$), 3.06$ (2H, $\left.\mathrm{NH}-\mathrm{CH}_{2}-\mathrm{CH}_{2}-\mathrm{CH}_{2}-\mathrm{N}\left(\mathrm{CH}_{3}\right)_{2} ; 2 \mathrm{H}, \mathrm{NH}-\mathrm{CH}_{2}-\mathrm{CH}_{2}-\mathrm{CH}_{3}\right), 2.64\left(2 \mathrm{H}, \mathrm{CO}-\mathrm{CH}-\mathrm{CH}_{2}-\mathrm{CO}\right), 2.18(2 \mathrm{H}$, 
$\left.\mathrm{NH}-\mathrm{CH}_{2}-\mathrm{CH}_{2}-\mathrm{CH}_{2}-\mathrm{N}\left(\mathrm{CH}_{3}\right)_{2}\right), 2.10\left(6 \mathrm{H}, \mathrm{NH}-\mathrm{CH}_{2}-\mathrm{CH}_{2}-\mathrm{CH}_{2}-\mathrm{N}\left(\mathrm{CH}_{3}\right)_{2}\right), 1.53\left(2 \mathrm{H}, \mathrm{NH}-\mathrm{CH}_{2}-\right.$

$\left.\mathrm{CH}_{2}-\mathrm{CH}_{2}-\mathrm{N}\left(\mathrm{CH}_{3}\right)\right), 1.43\left(2 \mathrm{H}, \mathrm{NH}-\mathrm{CH}_{2}-\mathrm{CH}_{2}-\mathrm{CH}_{3}\right), 0.82\left(3 \mathrm{H}, \mathrm{NH}-\mathrm{CH}_{2}-\mathrm{CH}_{2}-\mathrm{CH}_{3}\right)$;

FTIR (KBr) $\left[\mathrm{cm}^{-1}\right]: 3317$ ( $v \mathrm{NH}$ Amide), 1653 ( $v$, Amide I), 1538 ( $\delta$, Amide II), $2944\left(v_{\mathrm{as}} \mathrm{CH}_{3}\right.$, $\left.v_{\mathrm{as}} \mathrm{CH}_{2}\right) .{ }^{1} \mathrm{H}$ NMR and FTIR assignments of each synthesized polyaspartamide are displayed in the Supplementary Information.

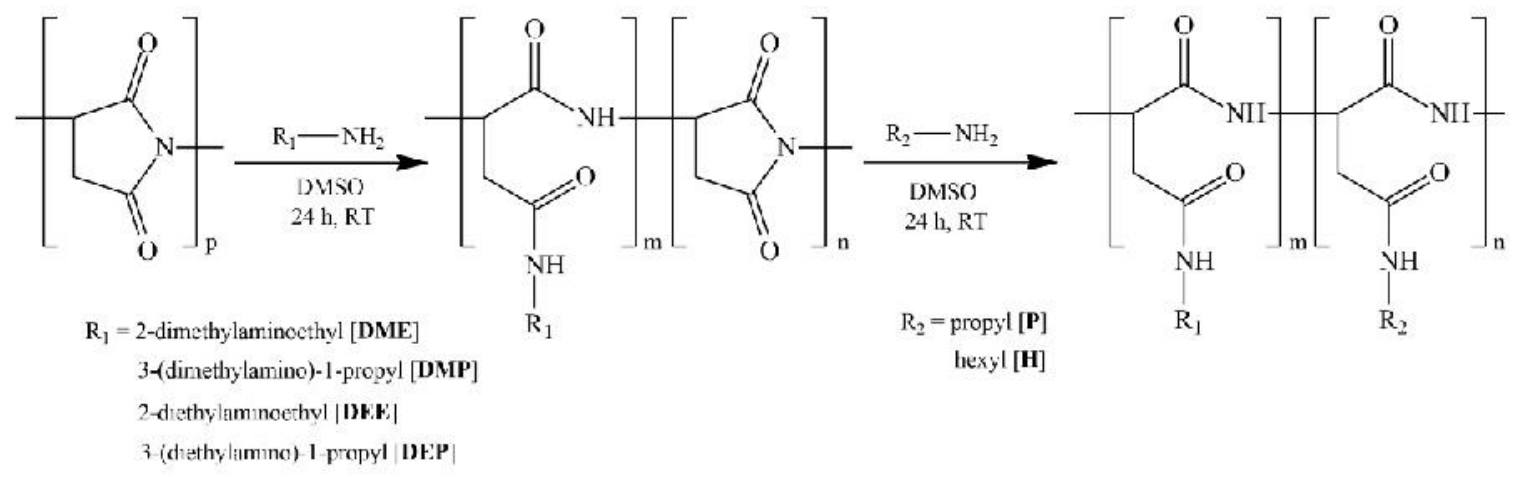

Scheme 1: Synthesis of cationic polyaspartamides

\subsubsection{Synthesis of cationic polyaspartamides with a fluorescence marker}

Fluorescent marking was used for the determination of the dissolution rate of the polymers at the $\mathrm{pH}$ of the stomach $(\mathrm{pH}=1.2)$ and the oral cavity $(\mathrm{pH}=6.8)$. At first, PSI was modified with the methyl ester of a fluorescent amino acid, L-tryptophan. $2.000 \mathrm{~g}(20.62 \mathrm{mmol})$ PSI and $0.053 \mathrm{~g}(0.207 \mathrm{mmol})$ tryptophan methyl ester hydrochloride were dissolved in $16.0 \mathrm{~g}$ of DMSO. When dissolution was complete, $1.0 \mathrm{~g}$ of $4 \mathrm{wt} \% \mathrm{H}_{3} \mathrm{PO}_{4} / \mathrm{DMSO}$ solution and $0.103 \mathrm{~g}$ of DBA $(0.79 \mathrm{mmol})$ were added dropwise, and the mixture was stirred at room temperature for $48 \mathrm{~h}$. Further steps were carried out in the same way as described in the case of non-marked polymers.

\subsubsection{Abbreviations}

Synthesized polymers were abbreviated as A\%B\%, where A and B respectively denote the repeating units of the polymers modified with dialkylaminoalkyl and alkyl side groups, 
including 3-(diethylamino)-1-propyl (DEP), 3-(dimethylamino)-1-propyl (DMP), 2-dimethylaminoethyl (DME), 2-diethylaminoethyl (DEE), propyl (P) and hexyl (H) groups while the subsequent numeric values refer to concentration ratio $(\mathrm{mol} \%)$ of the side groups. For instance, DMP90P10 means that PSI was modified first with $90 \mathrm{n} / \mathrm{n} \%$ 3-(dimethylamino)-1propylamine (DMP) and subsequently $10 \mathrm{n} / \mathrm{n} \% \mathrm{n}$-propylamine (P).

\subsection{Characterization}

\subsubsection{Chemical structure}

${ }^{1} \mathrm{H}$ NMR spectra of the polymers were recorded using a Bruker $500 \mathrm{MHz}$ spectrometer with 128 scans in $\mathrm{D}_{2} \mathrm{O}$ or DMSO- $\mathrm{d}_{6}$ (3 $\mathrm{wt} \%$ polymer solution). TMS (0.03 vol\%) was used as internal standard. FTIR spectra were recorded using a Bruker Tensor 27 FTIR spectrometer on $\mathrm{KBr}$ pellets $\left(\sim 1.5 \mathrm{mg}\right.$ polymer/250 mg KBr) from 4000 to $400 \mathrm{~cm}^{-1}$ with 128 scans and a resolution of $2 \mathrm{~cm}^{-1}$ for each sample.

\subsubsection{Thermal decomposition of the polymers}

Simultaneous thermogravimetric and differential scanning calorimetric analysis (TG/DSC) and mass spectrometric (MS) evolved gas analysis were carried out on the polymer samples using an STA 449 C Jupiter (Netzsch) thermoanalyzer coupled with a quadrupole mass-spectrometer QMS 403 C Aeolos. The measurements were carried out as described elsewhere [22,23]. Polymer powders of about $10 \mathrm{mg}$ were weighted into aluminum crucibles and then the samples were heated from 30 to $600{ }^{\circ} \mathrm{C}$ with a scanning rate of $10{ }^{\circ} \mathrm{C} \mathrm{min}-1$ under Ar atmosphere (with a total flow rate of $75 \mathrm{ml} \mathrm{min}^{-1}$ ).

\subsubsection{Calorimetric studies (DSC)}

Free films were prepared from the polymers by the evaporation of the solvent, 2-propanol, from their solutions. The samples were dried under vacuum at $25^{\circ} \mathrm{C}$ for $24 \mathrm{~h}$ prior testing. The glass transition temperature $\left(\mathrm{T}_{\mathrm{g}}\right)$ of the synthesized polymers was determined by differential 
scanning calorimetry (DSC). DSC curves were recorded by using a PYRIS Diamond Differential Scanning Calorimeter (PerkinElmer). The measurements were performed on $\sim 10 \mathrm{mg}$ samples in $\mathrm{N}_{2}$ atmosphere with a heating rate of $10^{\circ} \mathrm{C} \mathrm{min}^{-1}$ between -60 and $120{ }^{\circ} \mathrm{C}$. DSC curves were used for determination of the glass transition temperature of the polymers.

\subsubsection{Dissolution rate of the polymers}

Polyaspartamides marked with fluorescent tryptophan methyl ester were dissolved in 2-propanol at a concentration of $20 \mathrm{wt} \%$ and triethyl citrate was used as plasticizer (20 wt $\%$ based on the weight of the polymer). Subsequently the solutions were poured onto a glass plate bordered with a $1 \mathrm{~mm}$ stick silicone frame. Coated plates were dried at room temperature for $48 \mathrm{~h}$ before testing. The thickness of the coatings was measured with a micrometer.

The coated microscopic plates were immersed into $20 \mathrm{ml}$ of $\mathrm{HCl}$ solution $(\mathrm{pH}=1.2$, ionic strength, $\mathrm{I}=0.15 \mathrm{M}$ ) or PBS $(\mathrm{pH}=6.8$, ionic strength, $\mathrm{I}=0.15 \mathrm{M}$ ) and kept there for $20 \mathrm{~min}$ $\left(\mathrm{T}=37^{\circ} \mathrm{C}\right)$. The measurements were performed in continuously stirred vessels $\left(\mathrm{V}=50 \mathrm{~cm}^{3}\right)$, stirring rate was $200 \mathrm{rpm}$. Samples of $2 \mathrm{ml}$ were taken at predetermined time intervals, and replaced with $2 \mathrm{ml}$ of fresh buffer solution. The amount of dissolved polyaspartamides was determined by fluorescence spectroscopy (Perkin Elmer LS55 fluorescence spectrometer, $\lambda_{\text {ext }}: 280 \mathrm{~nm} ; \lambda_{\mathrm{em}}: 355 \mathrm{~nm}$ ). Dissolution rate constant of the polyaspartamides at given $\mathrm{pH}$ was calculated by the Noyes-Whitney equation [24]:

$$
\frac{C_{t}}{C_{\infty}}=1-e^{-k t}
$$

where $C_{t}$ is the concentration of the dissolved polymer at time $t$ and $C_{\infty}$ is the concentration of dissolved polymer at infinite time, $\mathrm{k}$ is the dissolution rate constant. Data points below $60 \%$ of dissolution were used for the calculation. 


\subsubsection{Cell viability}

Human prostatic carcinoma cell line (PC-3) and human embryonic kidney cell line (HEK293) were obtained from ATCC. Cells were cultured in DMEM supplemented with 10\% FBS, $2 \mathrm{mM}$ L-glutamine, $100 \mu \mathrm{g} / \mathrm{mL}$ streptomycin and $100 \mathrm{U} / \mathrm{mL}$ penicillin at $37^{\circ} \mathrm{C}$ in humidified air atmosphere with $5 \% \mathrm{CO}_{2}$. The cytotoxicity of the cationic polymers synthesized was evaluated by using MTT test performed as follows. Cells were collected from the culture flask by treating with trypsin-EDTA solution, then seeded in a 96-well plate at a density of 1000 cells per well in DMEM and cultured overnight. Aqueous polymer solutions were prepared and sterilized using a syringe filter (pore size: $0.2 \mu \mathrm{m}$ ). The culture medium in plate was replaced with fresh one and the polymer solutions were added to cells at final concentration between 0 and $125 \mu \mathrm{g} / \mathrm{ml}$. Sterile water was added instead of polymer solutions as control.

Cells were cultured in the presence of polymers in standard conditions for $72 \mathrm{~h}$, then the medium was replaced by the fresh one containing MTT reagent at a concentration of $0.5 \mathrm{mg} / \mathrm{ml}$. Cells were additionally cultured for $3 \mathrm{~h}$ to allow them to reduce MTT into water insoluble product (formazan) followed by the medium discarding and formazan dissolution with $100 \mu \mathrm{l}$ of DMSO per well. The absorbance of formazan solution in each well, which is proportional to the number of viable cells, was measured using an Infinite M200 PRO microplate analyser (Tecan) at wavelength $555 \mathrm{~nm}$. Cell viability was calculated as a percentage of control cells grown without polymers (100\% viability)

\subsubsection{Statistical analysis}

Results of the dissolution tests were analyzed statistically with GraphPad Prism software (version 5). Two-way ANOVA (with Bonferroni post-tests) analysis was applied. The values are expressed as means \pm standard deviation (SD). A level of $p \leq 0.05$ was taken as significant, $p \leq 0.01$ as very significant, and $p \leq 0.001$ as highly significant. 


\section{RESULTS AND DISCUSSION}

\subsection{Chemical structure}

Polyaspartamides with tertiary amine side groups were prepared from polysuccinimide to obtain polymers with sufficiently low glass transition temperature for further use as tablet coating. Together with dialkylaminoalkyl side groups, alkyl side groups were introduced onto the polyaspartamide chains to adjust thermal properties and aqueous solubility of the polymers. Using PSI enabled us to synthesize polyaspartamides with large chemical variety under mild reaction conditions. The yield was high (>75\%) independently of composition. The structure of the polymers was confirmed by ${ }^{1} \mathrm{H}$ NMR and FTIR spectroscopy (Fig. 1). 
a)

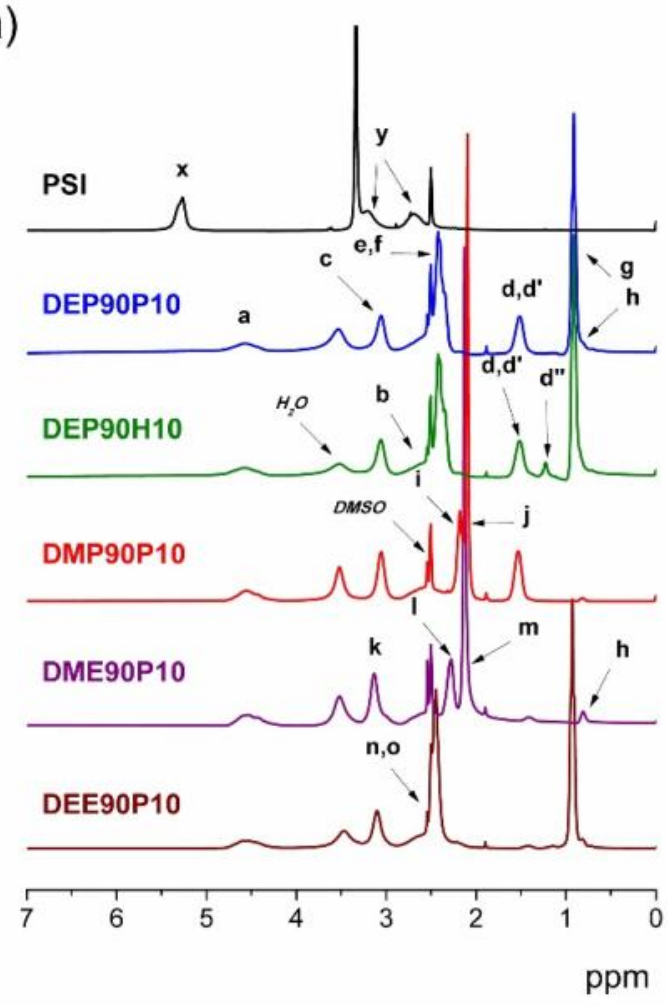

c)

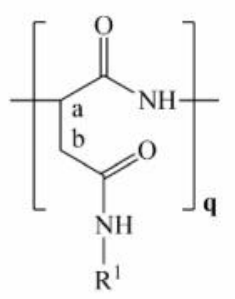

PASPAM

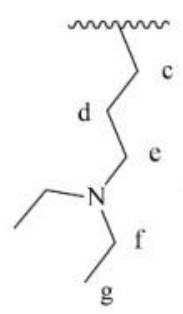

DEP b)

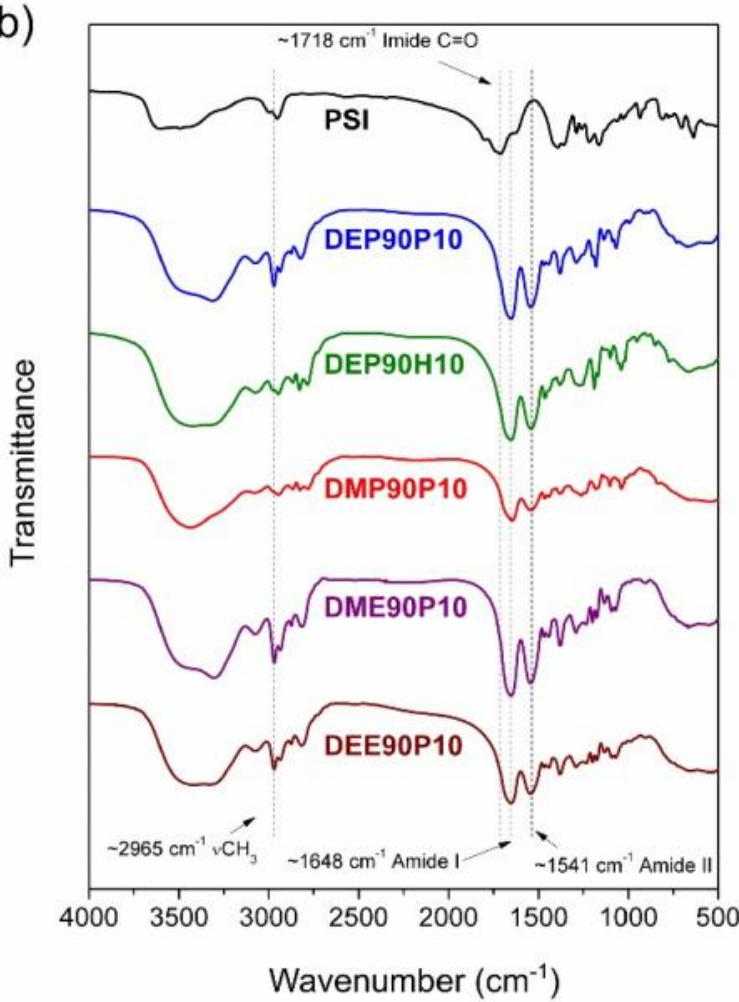

PSI

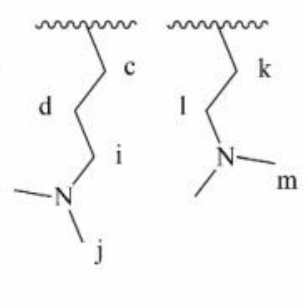

DME

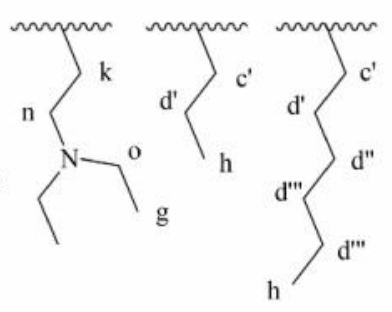

DEE P H

Fig. 1: a) ${ }^{1} \mathrm{H}$ NMR and b) FTIR spectra of PSI and the synthesized cationic poly(aspartamide)s (DEP90P10; DEP90H10; DMP90P10; DME90P10; DEE90P10), and c) chemical structure of succinimide, the aspartamide repeating unit and the side groups (each polymer contains two types of the presented side groups)

In the NMR spectra (Fig 1a), the methylene peaks (y) of succinimide repeating unit of PSI appear at $\sim 2.70$ and $\sim 3.21 \mathrm{ppm}$ as inequivalent methylene protons, while the broad peak at $\sim 5.27 \mathrm{ppm}(\mathrm{x})$ corresponds to the methyne proton of the succinimide ring. Comparing the 
spectra of polysuccinimide and the polyaspartamides one can observe that the peak at $\sim 5.27 \mathrm{ppm}(\mathrm{x})$ disappeared from the spectra of the polyaspartamides indicating that all of the succinimide rings were opened during modification. The broad peak at $\sim 4.55 \mathrm{ppm}$ (a) belongs to the methyne proton of the aspartamide units, while the signal at $\sim 2.64 \mathrm{ppm}$ (b) corresponds to the methylene protons. Signals assigned to dialkylaminoalkyl [0.92 (g), $1.51(\mathrm{~d}), 2.10(\mathrm{j}, \mathrm{m})$, 2.18 (i), 2.29 (l), 2.35 (e), 2.41 (f), 2.46 (n, o), 3.05 ppm (c), 3.11 (k)] and n-alkyl side groups [0.83 (h), 1.23 (d"), 1.43 (d'), 3.05 ppm (c')] are identified in the spectra of polyaspartamides. The ratio of the dialkylaminoalkyl and the n-alkyl aspartamide repeating units was calculated by comparing the integral area of the peak at $\sim 0.83 \mathrm{ppm}(\mathrm{h})$ assigned to the methyl protons of the alkyl side groups with the peak at $\sim 4.55 \mathrm{ppm}$ (a') belonging to the methyne proton of aspartamide repeating units. The calculated composition of polymers, i.e. the molar ratio of $n$-alkyl side groups to the repeating units, $\left(X_{\text {calc }}\right.$, Table 1$)$ agrees well with feed composition ( $X_{\text {feed }}$, Table 1 ). The molar ratio of dialkylaminoalkyl side groups to the repeating units is $1-X_{\text {calc }}$. 
Table 1 Composition, molecular weight and thermal properties of the synthesized cationic polyaspartamides

\begin{tabular}{|c|c|c|c|c|c|}
\hline \multirow{2}{*}{ Sample name } & \multicolumn{2}{|c|}{ Composition } & \multirow{2}{*}{$M_{v, P A S P A m}(k D a)$} & \multirow{2}{*}{$\mathrm{T}_{\mathrm{d}}\left({ }^{\circ} \mathrm{C}\right)$} & \multirow{2}{*}{$\mathrm{Tg}\left({ }^{\circ} \mathrm{C}\right)$} \\
\hline & $X_{\text {feed }}$ & $X_{\text {calc }}$ & & & \\
\hline DE P50P50 & 0.48 & 0.48 & 57.0 & 206 & 40.7 \\
\hline DE P90P10 & 0.11 & 0.11 & 66.6 & 201 & 27.5 \\
\hline DE P9OH 10 & 0.10 & 0.11 & 67.8 & 201 & 28.0 \\
\hline DM P90P 10 & 0.09 & 0.09 & 58.9 & 197 & 20.6 \\
\hline DE E 90P10 & 0.10 & 0.10 & 62.8 & 192 & 32.6 \\
\hline DM E $90 P 10$ & 0.11 & 0.12 & 55.1 & 182 & 30.4 \\
\hline
\end{tabular}

$X_{\text {feed }}$ : molar ratio of $n$-alkyl side groups to the repeating units as calculated from the composition of the reaction mixture (the feed); $X_{\text {calc }}$ : molar ratio of $n$-alkyl side groups to the repeating units as calculated from the ${ }^{1} \mathrm{H}$ NMR data, the average error of ${ }^{1} \mathrm{H}$ NMR measurements was $\pm 2 \%$; $M_{v, \text { PASPAm }}$ : molecular weight of the polymers calculated from intrinsic viscosity, the average error of viscometry measurements was $\pm 2 \%$; $T_{d}$ : thermal decomposition temperature; $T_{g}$ : glass transition temperature

According to FTIR results, the characteristic absorption band of the imide ring is detected at $1718 \mathrm{~cm}^{-1}$ in the case of PSI, while it is not observable in the spectra of polyaspartamides proving that ring-opening of the succinimide repeating units was complete as shown in Fig. $1 \mathrm{~b}$. The absorption bands at $1648 \mathrm{~cm}^{-1}$ (Amide I) and $1541 \mathrm{~cm}^{-1}$ (Amide II) correspond to the amide bonds of these polymers. The band at $2965 \mathrm{~cm}^{-1}$ assigned to the asymmetric stretching of $\mathrm{CH}_{3}$ groups indicates the presence of the side groups introduced. The results of ${ }^{1} \mathrm{H}$ NMR and FTIR analysis show that by our synthesis method cationic polyaspartamides can be synthesized with the desired structure at complete conversion.

Assuming that the degree of polymerization of PSI $\left(M_{\mathrm{PSI}} / \mathrm{M}_{\mathrm{SI}}=\mathrm{DP} \mathrm{P}_{\mathrm{PSI}} \simeq 300\right)$ does not change during the modification reactions, molecular weight of the synthesized polyaspartamides $\left(M_{v, \text { PASPAm }}\right)$ was calculated by the following equation: 


$$
M_{V, P A S P A m}=M_{V, P S I} \times\left(\frac{n \times M_{A}+m \times M_{B}}{M_{S l}}\right)
$$

where $M_{A}, M_{B}$ and $M_{S I}$ are the molecular weight of the two different types of repeating units in polyaspartamides and succinimide repeating unit, $\mathrm{n}$ and $\mathrm{m}$ are the mole fraction of the repeating units calculated from the ${ }^{1} \mathrm{H}$ NMR spectra (Table 1).

\subsection{Thermal decomposition}

The thermal decomposition of PSI, PASP and the cationic polyaspartamides synthesized was studied in the temperature range of $30-600{ }^{\circ} \mathrm{C}$ by simultaneous TG/DSC/MS technique in order to prove that they are stable even at the highest temperatures used in pharmaceutical processes, particularly in tablet coating.
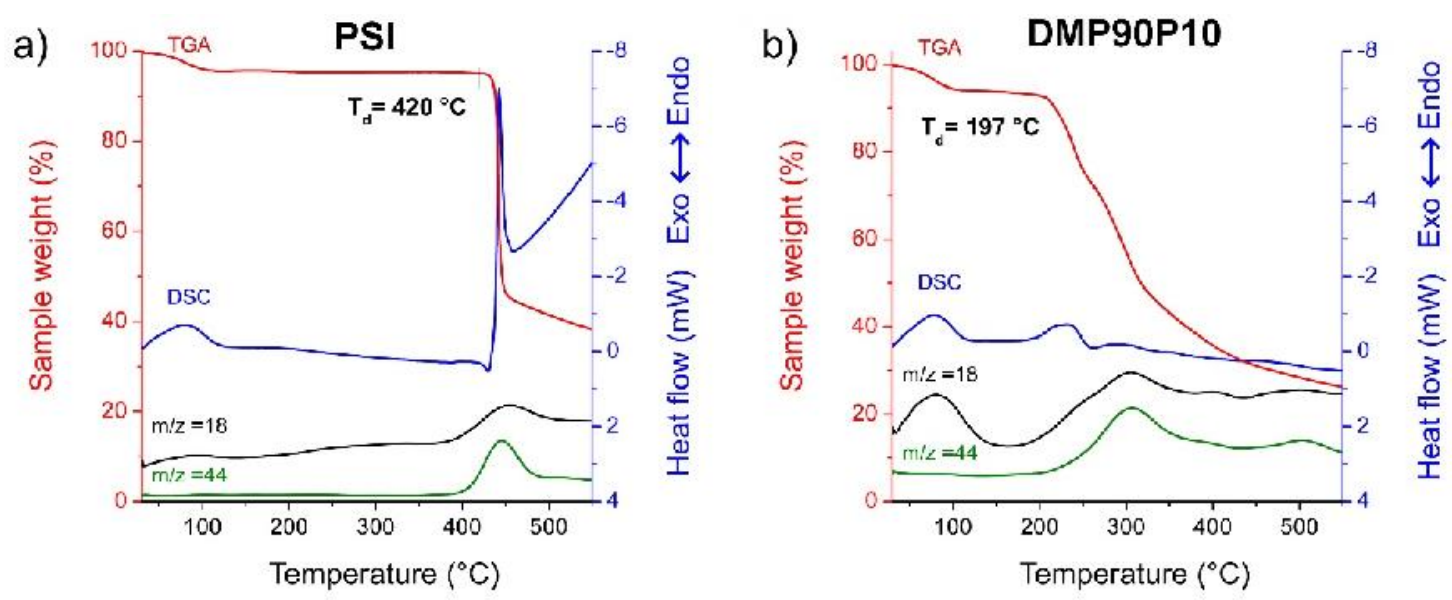

Fig. 2: TG/DSC/MS analysis of a) PSI and b) DMP90P10. Ion thermograms of $\mathrm{H}_{2} \mathrm{O}(\mathrm{m} / \mathrm{z}=18)$ and $\mathrm{CO}_{2}(\mathrm{~m} / \mathrm{z}=44)$ are indicated. Heating rate was $10{ }^{\circ} \mathrm{C} \mathrm{min}^{-1}$

In accordance with the literature [25], PSI decomposes in a single-stage process (Fig. 2a). Weight loss recorded up to $\sim 120{ }^{\circ} \mathrm{C}$ is attributed to the elimination of adsorbed water confirmed by the $\mathrm{m} / \mathrm{z}=18$ ion signal and the endothermic heat effect appearing at $\sim 100{ }^{\circ} \mathrm{C}$. The sharp endothermic peak as well as the main peak of the $\mathrm{m} / \mathrm{z}=44$ ionic signal correspond to the release of $\mathrm{CO}_{2}$ and the decomposition of PSI around $420^{\circ} \mathrm{C}$. As a representative example of 
polyaspartamides, DMP90P10 shows a much lower thermal decomposition temperature and a multi-step process (Fig. 2b). Weight loss occurs at about $100{ }^{\circ} \mathrm{C}$ due to the elimination of residual water content similarly to PSI, while a large mass loss and an endothermic peak at $197^{\circ}$ indicate the beginning of thermal degradation. Further analysis of the decomposition steps is beyond the scope of this paper, but we conclude that all the synthesized cationic polyaspartamides are stable to about $190-210^{\circ} \quad$ (Table 1, please see also the Supplementary Information), which is important for the future application of the polymers as pharmaceutical coatings. Each temperature of decomposition $\left(T_{d}\right)$ is higher than the highest temperatures applied generally in the tablet coating step $\left(\sim 60^{\circ} \mathrm{C}\right)$, and $\mathrm{T}_{\mathrm{d}}$ values are above temperatures at which dry heat sterilization is carried out $\left(160-180{ }^{\circ} \mathrm{C}\right)[26]$, thus cationic polyaspartamides can be processed without chemical degradation.

\subsection{G lass transition temperature}

Knowledge of the glass transition temperature $\left(\mathrm{T}_{\mathrm{g}}\right)$ of the cationic polyaspartamides is essential for efficient film formation, moreover, the $T_{g}$ also determines the usability of the final product as tablet coating. Accordingly, the $\mathrm{T}_{\mathrm{g}}$ of polysuccinimide (PSI), poly(aspartic acid) (PASP) and the cationic polyaspartamides synthesized was determined and compared to establish a correlation between the $\mathrm{T}_{\mathrm{g}}$ and the chemical structure of the polymers (the general structure of the polymers is shown in Fig 3a). Polysuccinimide (PSI) is an amorphous material [27], but the $\mathrm{T}_{\mathrm{g}}$ of PSI cannot be detected below the decomposition temperature of the polymer (Fig. 3b, $\mathrm{T}_{\mathrm{d}} \sim 400{ }^{\circ} \mathrm{C}$ ). We have found similar results also in the literature [25]. Because of hindered bond rotation in the succinimide ring, the backbone of the PSI is very stiff and the activation energy of the segmental motion is larger than the dissociation energy of chemical bonds in the polymer chain, therefore the polymer decomposes before reaching its glass transition temperature. As shown in Fig. $3 \mathrm{~b}$, the $\mathrm{T}_{\mathrm{g}}$ of the PASP was found to be $85^{\circ} \mathrm{C}$ indicating the opening of the ring of the succinimide repeating units and thus the formation of 
a much flexible polyamide backbone results in a dramatic decrease of $\mathrm{T}_{\mathrm{g}}$. Data obtained on the sodium salt of poly(aspartic acid) derivatives modified with hexadecylamine [28] demonstrates that not only the opening of the ring, but also the type and concentration of side groups have an effect on $\mathrm{T}_{\mathrm{g}}$. Thus, we compared the $\mathrm{T}_{\mathrm{g}}$ of unsubstituted PASP with several substituted polymers to establish structure vs. $\mathrm{T}_{\mathrm{g}}$ correlation. 
a)
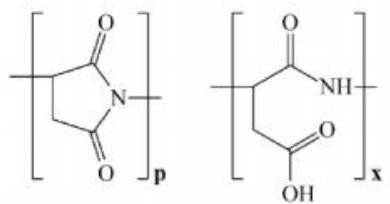

PSI

PASP

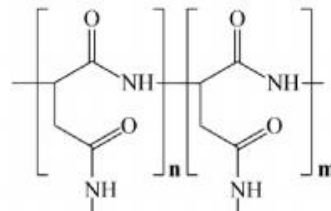

b)

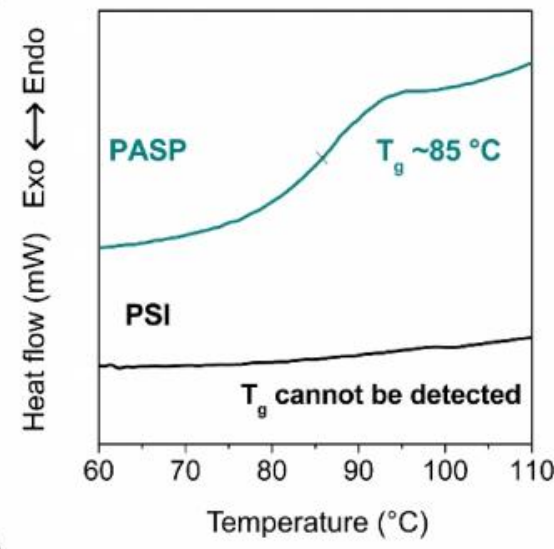

d)

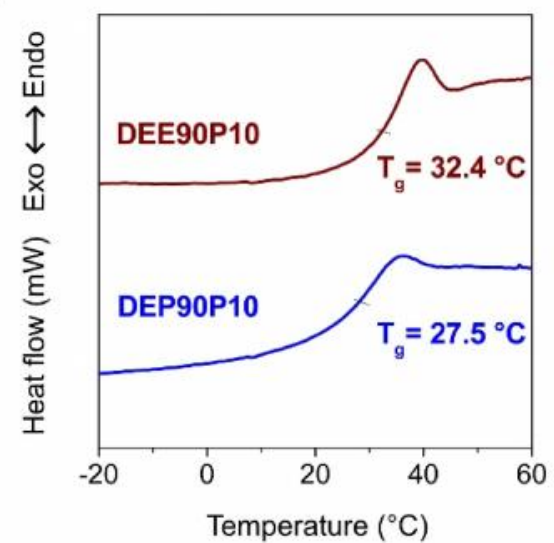

f)

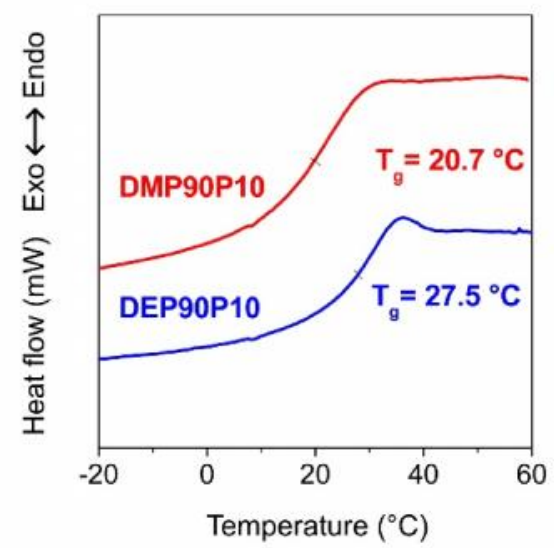

DEP50P50: $R_{1}$ : propylene DMP90P10: $R_{1}$ : propylene

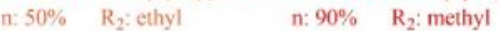
m: $50 \% \quad R_{3}$ : propyl $\quad m: 10 \% \quad R_{3}:$ propyl DEP90P10: $R_{1}$ : propylene DME90P10: $R_{1}$ : ethylene n: $90 \% \quad \mathrm{R}_{2}$ : ethyl $\quad \mathrm{n}: 90 \% \quad \mathrm{R}_{2}$ : methyl $\mathrm{m}: 10 \% \quad \mathrm{R}_{3}$ : propyl $\quad \mathrm{m}: 10 \% \quad \mathrm{R}_{3}$ : propyl DEP90H10: $\mathrm{R}_{1}$ : propylene DEE90P10: $\mathrm{R}_{1}$ : ethylene n: $90 \% \quad R_{2}$ : ethyl $\quad n: 90 \% \quad R_{2}$ : ethyl

$\begin{array}{llll}\mathrm{m}: 10 \% & \mathrm{R}_{3}: \text { hexyl } & \mathrm{m}: 10 \% & \mathrm{R}_{3} \text { : propyl }\end{array}$

c)

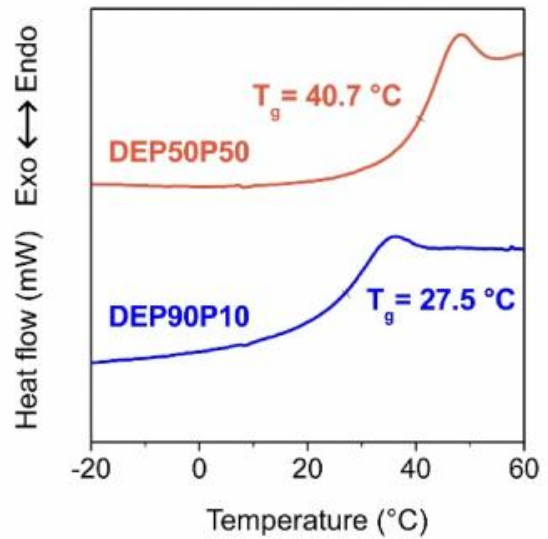

e)

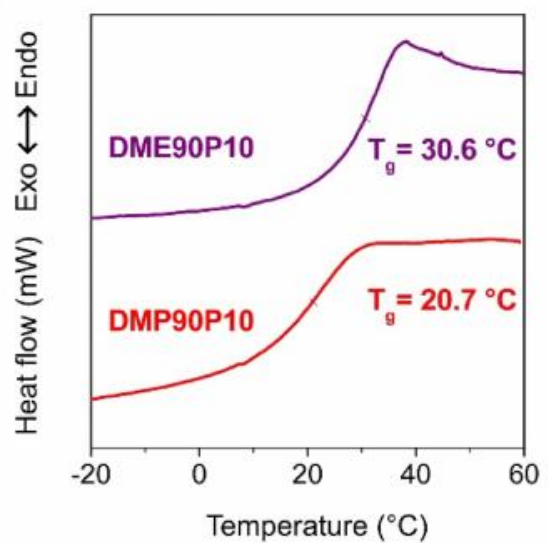

g)

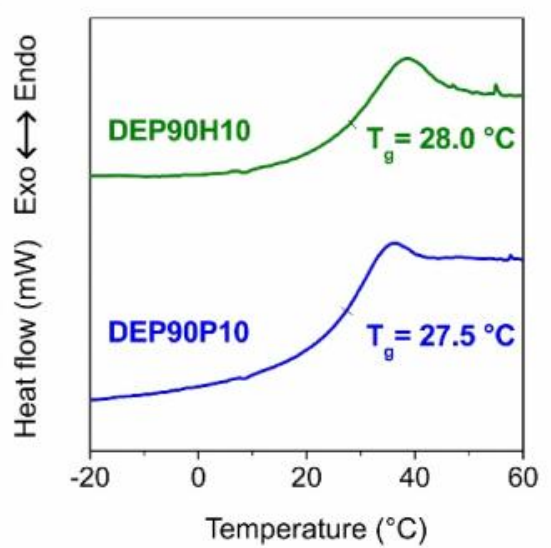

Fig. 3: a) General chemical formula and b-g) DSC temperature scans of PSI, PASP and the cationic polyaspartamides synthesized 
The $\mathrm{T}_{\mathrm{g}}$ values of PASP and the polyaspartamides are detected at more than $300{ }^{\circ} \mathrm{C}$ lower than the $T_{d}$ of PSI (Fig. 3, Table 1). Consequently, this significant depression of $T_{g}$ is mainly due to the opening of the succinimide rings. However, the $\mathrm{T}_{\mathrm{g}}$ of the polyaspartamides $\left(20-40{ }^{\circ} \mathrm{C}\right)$ is considerably lower than the $\mathrm{T}_{\mathrm{g}}$ of PASP $\left(85^{\circ} \mathrm{C}\right)$ indicating that the side groups have a remarkable effect on the glass transition as shown in Fig. 3c-g. Side groups act as internal plasticizers by screening intermolecular interactions among the polymer chains. The magnitude of internal plasticization depends on the type and the concentration of the side groups. $\mathrm{T}_{\mathrm{g}}$ decreases with increasing concentration of dialkylaminoalkyl side groups at the expense of n-alkyl side groups $\left(\mathrm{DEP} 50 \mathrm{P} 50 \rightarrow\right.$ DEP90P10, Fig. 3c) and $\mathrm{T}_{\mathrm{g}}$ also decreases with increasing chain length of the alkylene unit of the dialkylaminoalkyl side groups from ethylene to propylene (Fig. 3d, DEE90P10 $\rightarrow$ DEP90P10; Fig. 3e, DME90P10 $\rightarrow$ DMP90P10). These results are consistent with those obtained on cationic polyacrylates [5]. In contrast, changing the $\mathrm{N}$-methyl groups of dialkylaminoalkyl side groups to $\mathrm{N}$-ethyl groups leads to an increase in $\mathrm{T}_{\mathrm{g}}$ (Fig. 3f, DMP90P10 $\rightarrow$ DEP90P10) which can be explained by the fact, that the diethylaminoalkyl side groups is bulkier than the dimethylamino ones resulting in decreased chain mobility. $\mathrm{T}_{\mathrm{g}}$ practically does not change when the chain length of the alkyl side groups increases from propyl to hexyl (Fig. 3g, DEP90P10 $\rightarrow$ DEP90H10). The length of the alkyl side groups is expected to affect the glass transition temperature of the polyaspartamides, but the results show that this effect is marginal at low alkyl side group concentrations. To conclude, the $\mathrm{T}_{\mathrm{g}}$ of cationic polyaspartamides can be adjusted between 20 and $40{ }^{\circ} \mathrm{C}$ by the proper selection of its chemical structure.

As $T_{g}$ values of polyaspartamides were found close to the room temperature, only a small amount $(\sim 10 \mathrm{wt} \%$ for the polymer) of an external plasticizer is sufficient to prepare mechanically stable polymer films by solvent evaporation. The detailed characterization of the prepared polyaspartamide films, including thermal analysis, tensile testing, the determination 
of water uptake will be discussed in another paper. Here we demonstrate only the composition and $\mathrm{pH}$-dependent dissolution rate of the films.

\subsection{Dissolution of cationic polyaspartamides}

The thermal stability and the controllable glass transition temperature of polyaspartamides make them promising candidates as film forming materials for tablet coatings. In addition to these properties, taste masking requires a moderate dissolution rate of the polymer film at the prevalent $\mathrm{pH}$ in the mouth $(\mathrm{pH}=6.8)$. On the other hand, dissolution of the coating has to be as fast as possible at the acidic $\mathrm{pH}$ of the stomach to provide rapid drug release and therefore fast therapeutic action. Thus, the determination of the dissolution profile of polyaspartamides at $\mathrm{pH}=6.8$ and $\mathrm{pH}=1.2$ is an essential requirement for this application. Since a well-established method for monitoring the dissolution of such polymers does not exist, we developed a selective and sensitive method to characterize the dissolution rate of polyaspartamides by the fluorescent marking of the polymers. The marker should not affect the solubility of the polymer, but must provide easy detection. Accordingly, we chose the methyl ester of the essential amino acid tryptophan (TrpOMe) as a fluorescent marker. Due to its relatively high quantum yield, only a small amount of TrpOMe must be grafted onto the polymer chains to achieve a low limit of quantitation thus we expected that the effect of modification on the physicochemical properties of the polymer is insignificant. Moreover, contrary to the reaction of other fluorescent markers, e.g. 3-amino-9-ethyl carbazole which can be introduced into the PASP chain by a complicated synthetic pathway $[29,30]$, tryptophan can react with PSI under mild reaction conditions [31].

Three of the synthesized polyaspartamides with the best film-forming properties were labeled with TrpOMe (TDMP90P09, TDEP90P09 and TDEP90H09) and glass plates were coated with their films (Fig. 4a, thickness of the films was $92 \pm 11 \mu \mathrm{m}$ ). The dissolution rate of the polymers was determined at the $\mathrm{pH}$ of the oral cavity $(\mathrm{pH}=6.8$, Fig. $4 \mathrm{~b})$ and the stomach 
$(\mathrm{pH}=1.2$, Fig. $4 \mathrm{c})$. Comparing the curves of Fig. $4 \mathrm{~b}$, less than $15 \%$ of the films dissolves in 30 seconds - the time at which the taste masking efficiency must be assessed [1] - thus we can expect, that tablet coatings based on these polyaspartamides can mask the unpleasant taste of drugs during the residence time in the mouth. Dissolution of the polymers shows slight structure dependence, as shown in Fig. 4b. There is no difference between the curves before reaching 1 min ( $p>0.05)$, however dissolution profile of TDMP90P09 significantly differs from that of TDEP90P09 and TDEP90H09 at the time interval of 1-2.5 min $(\mathrm{p}<0.001)$ and a noticeable, but far less significant difference can be observed if we compare profiles of TDEP90P09 and TDEP90H09 (1.25-2 min, $\mathrm{p}<0.05)$. Dissolution rate constants calculated by the NoyesWhitney equation (Eq. 2) are in line with this observation $\left(\mathrm{K}_{\text {TDMP 90P 09 }}=0.9 \mathrm{~min}^{-1}\right.$, $\left.\mathrm{k}_{\text {TDEP 90P } 09}=0.6 \mathrm{~min}^{-1}, \mathrm{k}_{\text {TDEP } 90 \mathrm{H} 09}=0.5 \mathrm{~min}^{-1}\right)$. The $\mathrm{pH}$-dependence of the dissolution of cationic polyaspartamides is much stronger, as shown in Fig. 4c. The chosen polymer, TDEP90H09 dissolves much faster at $\mathrm{pH}=1.2(\sim 80 \%$ at $2 \mathrm{~min})$ than at $\mathrm{pH}=6.8(\sim 55 \%$ at $2 \mathrm{~min})$ demonstrating that tablet coatings based on these polymers would not hinder the liberation of the drug at the $\mathrm{pH}$ of the stomach. A highly significant difference can be observed between the curves at the time interval of $0.5-3 \min ((\mathrm{p}<0.001)$, and consequently, dissolution rate constants largely differ from each other $\left(\mathrm{k}_{\mathrm{pH}=1.2}=1 \mathrm{~min}^{-1}, \mathrm{k}_{\mathrm{pH}=6.8}=0.5 \mathrm{~min}^{-1}\right)$. These results indicate that cationic polyaspartamides synthesized have considerable potential as starting materials of tablet coatings providing taste masking in the mouth and rapid liberation of the drug in the stomach. 
a)

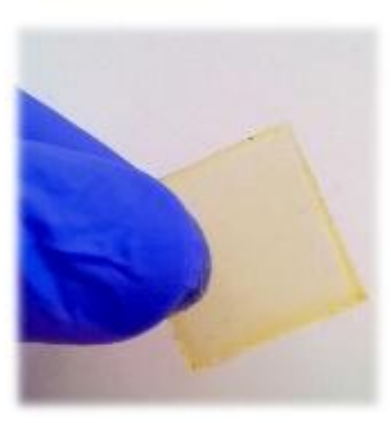

b)

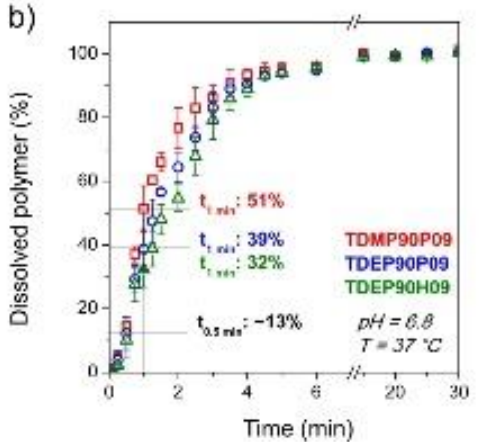

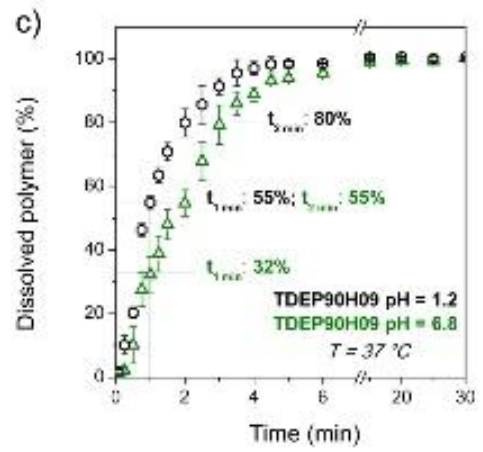

Fig. 4: a) Cationic polyaspartamide film on a glass plate and b) effect of the polymer composition and c) the $\mathrm{pH}$ on the dissolution profile of the polyaspartamide films

\subsection{Cell viability study}

PC-3 and HEK-293 cells were used as model cells for primary assessment of biocompatibility of polymers $[32,33]$. The effect of cationic polyaspartamide synthesized on cell viability was studied by using MTT proliferation assay. Fig. 5 shows concentrationviability curves for DMP90P10, DEP90P10 and DEP90H10 analyzed in dissolution tests. Data for other polyaspartamides DEP50P50, DME90P10 and DEE90P10 are shown in Figure S3 of Supplementary Information. The cationic polyaspartamides did not decrease significantly the viability of both PC-3 and HEK-293 cells within the concentration range studied (up to 125 $\mu \mathrm{g} / \mathrm{ml}$ ) during 72-hour cell culturing. As previously shown, polyethyleneimine, an other synthetic cationic polymer with similar molecular weight $(25 \mathrm{kDa})$ induced $50 \%$ cell loss at the concentration as low as $2 \mu \mathrm{g} / \mathrm{ml}$, indicating almost two orders of magnitude lower cytotoxicity of the cationic polyaspartamides synthesized [34]. Furthermore, an increase in cell proliferation up to $30 \%$ appeared for some of our polymers similarly to that observed for PASP conjugate with $\gamma$-amino butyric acid [35]. These preliminary data on biocompatibility support the further use of polymers synthesized while detailed study about structure-dependent biological characteristics of cationic polyaspartamides is reported elsewhere [34]. 

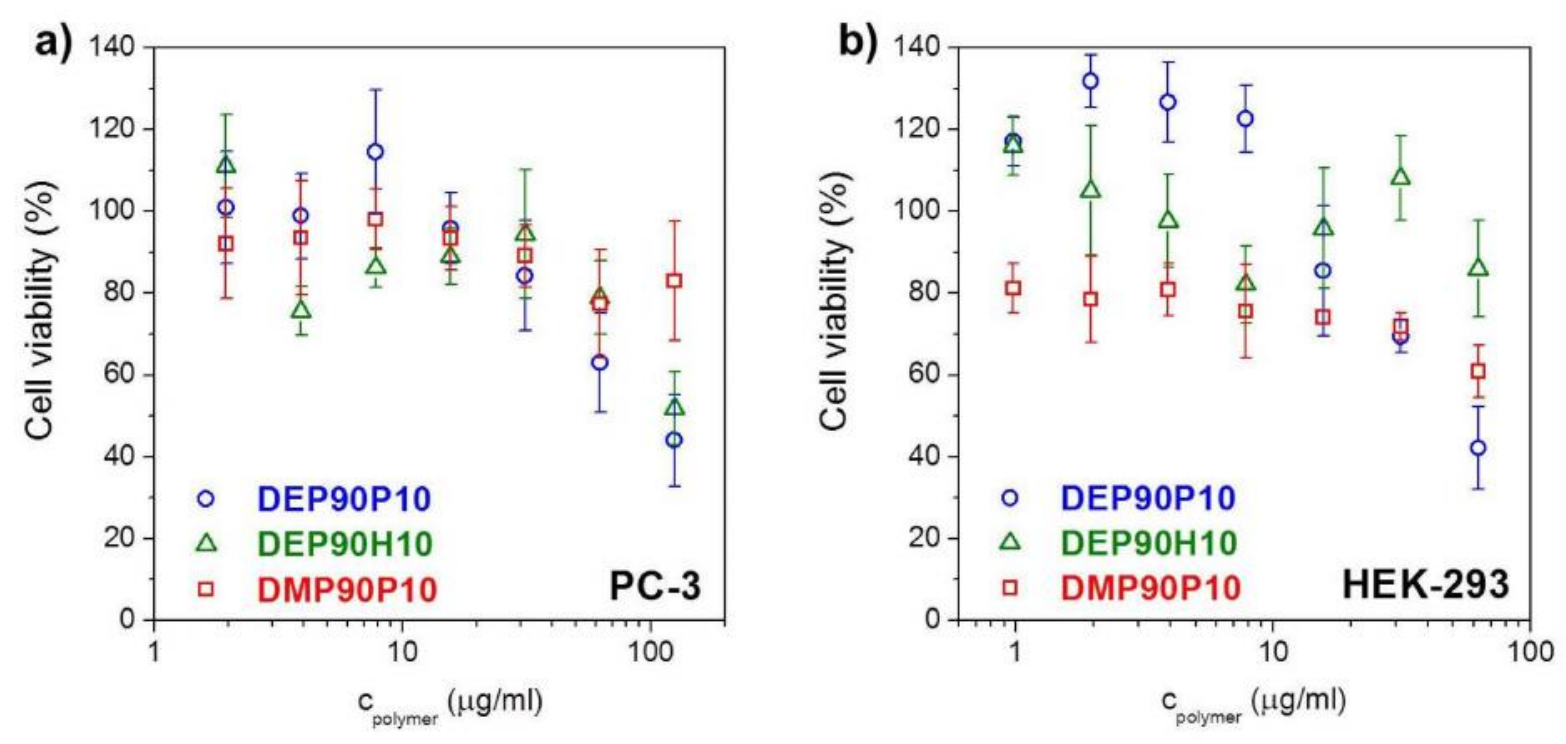

Fig. 5: Effect of DMP90P10, DEP90P10 and DEP90H10 on viability of a) PC-3 and b) HEK293 cells determined by MTT assay, $\mathrm{p}<0.05$

\section{CONCLUSION}

A wide variety of cationic polyaspartamides with dialkylaminoalkyl and alkyl side groups was synthesized. The structure of the polymers was confirmed by ${ }^{1} \mathrm{H}$ NMR and FTIR spectroscopy and the results demonstrated that the desired composition can be achieved with complete conversion by our synthesis method. The $T_{\mathrm{g}}$ of the polymers was adjusted to around room temperature by choosing the proper combination of side groups. Polyaspartamides obtained have good thermal stability, $\mathrm{T}_{\mathrm{d}}$ values of the polymers $\left(\sim 190-210{ }^{\circ} \mathrm{C}\right)$ were found to be significantly higher than temperatures applied in tablet coating processes $\left(\sim 60{ }^{\circ} \mathrm{C}\right)$. A method based on fluorescent labeling was developed to characterize the composition and $\mathrm{pH}$ dependence of dissolution kinetics of the cationic polyaspartamides synthesized. Owning to their thermal and dissolution properties, as well as their low cytotoxicity on PC3 and HEK-293 cell lines, cationic polyaspartamides can serve as alternatives of polyacrylates in entero-soluble 
film coatings due to their multiple advantages, such as easy functionalization and adjustable physical and chemical properties. Synthesis of polyaspartamide films and characterization of their properties from pharmaceutical point of view will be discussed in detail in another paper.

\section{ACKNOWLEDGEMENT}

Supports from the Hungarian Grant OTKA PD76401 (Hungarian Scientific Research Fund), the TÁMOP 4.2.1/B-09/1/KMR-2010-0002 (New Széchenyi Plan) and the FP7-PEOPLE2010-IRSES269267 (Marie Curie International Research Staff Exchange Scheme) project are acknowledged. András Szilágyi thanks the support of the János Bolyai Research Scholarship of the Hungarian Academy of Sciences. Mikhail Varfolomeev and Alexander Gerasimov acknowledge the support of Russian Government Program of Competitive Growth of Kazan Federal University.

\section{REFERENCES}

[1] M. Pein, M. Preis, C. Eckert, F.E. Kiene, Taste-masking assessment of solid oral dosage forms-A critical review, Int. J. Pharm. 465 (2014) 239-254.

[2] S. Joshi, H.U. Petereit, Film coatings for taste masking and moisture protection, Int. J. Pharm. 457 (2013) 395-406.

[3] O. Bley, J. Siepmann, R. Bodmeier, Protection of moisture-sensitive drugs with aqueous polymer coatings: Importance of coating and curing conditions, Int. J. Pharm. 378 (2009) 5965.

[4] E. Borbás, A. Balogh, K. Bocz, J. Müller, É. Kiserdei, T. Vigh, B. Sinkó, A. Marosi, A. Halász, Z. Dohányos, L. Szente, G.T. Balogh, Z.K. Nagy, In vitro dissolution-permeation evaluation of an electrospun cyclodextrin-based formulation of aripiprazole using $\mu$ Flux $^{\mathrm{TM}}$, Int. J. Pharm. 491 (2015) 180-189. 
[5] F. Fleischhaker, A.P. Haehnel, A.M. Misske, M. Blanchot, S. Haremza, C. BarnerKowollik, Glass-transition-, melting-, and decomposition temperatures of tailored polyacrylates and polymethacrylates: General trends and structure-property relationships, Macromol. Chem. Phys. 215 (2014) 1192-1200.

[6] O. Bley, R. Bodmeier, J. Siepmann, Characterization of moisture-protective polymer coatings using differential scanning calorimetry and dynamic vapor sorption, J. Pharm. Sci. 98 (2009) 651-664.

[7] M. Cerea, W. Zheng, C.R. Young, J.W. McGinity, A novel powder coating process for attaining taste masking and moisture protective films applied to tablets, Int. J. Pharm. 279 (2004) 127-139.

[8] Y. Nakano, A. Maeda, S. Uchida, N. Namiki, Preparation and evaluation of unpleasant taste-masked pioglitazone orally disintegrating tablets., Int. J. Pharm. 446 (2013) 160-165.

[9] K. Nollenberger, J. Albers, Poly(meth)acrylate-based coatings, Int. J. Pharm. 457 (2013) $461-469$.

[10] F.L. Buchholz, Polyacrylamides and Poly(Acrylic Acids), in: Ullmann's Encycl. Ind. Chem., 2000: pp. 501-514.

[11] O. Nuyken, G. Swift, Polymers of Acrylic acid, Methacrylic acid, Maleic acid, and Their Derivatives, in: Hans R. Kricheldorf, O. Nuyken, G. Swift (Eds.), Handb. Polym. Synth. 2nd Ed., 2005: pp. 241-332.

[12] B. Gyarmati, B. Vajna, Á. Némethy, K. László, A. Szilágyi, Redox- and pH-responsive cysteamine-modified poly(aspartic acid) showing a reversible sol-gel transition, Macromol. Biosci. 13 (2013) 633-640.

[13] B. Gyarmati, E.Z. Mészár, L. Kiss, M.A. Deli, K. László, A. Szilágyi, Supermacroporous chemically cross-linked poly(aspartic acid) hydrogels, Acta Biomater. 22 
(2015) 32-38.

[14] T. Nakato, M. Tomida, M. Suwa, Y. Morishima, Preparation and characterization of dodecylamine-modified poly(aspartic acid) as a biodegradable water-soluble polymeric material, Polym. Bull. 391 (2000) 385-391.

[15] Á. Némethy, K. Solti, L. Kiss, B. Gyarmati, M.A. Deli, E. Csányi, A. Szilágyi, pH- and temperature-responsive poly(aspartic acid)-1-poly(N-isopropylacrylamide) conetwork hydrogel, Eur. Polym. J. 49 (2013) 2392-2403.

[16] J.R. Moon, Y.S. Jeon, D.J. Chung, In situ gelling and drug release behavior from novel temperature-sensitive polyaspartamides, Macromol. Res. 19 (2011) 515-518.

[17] K. Itaka, T. Ishii, Y. Hasegawa, K. Kataoka, Biodegradable polyamino acid-based polycations as safe and effective gene carrier minimizing cumulative toxicity, Biomaterials. 31 (2010) 3707-3714.

[18] Q.V. Bach, J. Moon, D.S. Lee, J. Kim, Lower critical solution temperature behavior of amphiphilic copolymers based on polyaspartamide derivatives, J. Appl. Polym. Sci. 107 (2008) $509-513$.

[19] J.R. Moon, Y.H. Park, J. Kim, Synthesis and characterization of novel thermo- and pHresponsive copolymers based on amphiphilic polyaspartamides, J. Appl. Polym. Sci. 111 (2008) 998-1004.

[20] J.R. Moon, J. Kim, Biodegradable stimuli-responsive hydrogels based on amphiphilic polyaspartamides with tertiary amine pendent groups, Polym. Int. (2010) 630-636.

[21] J. Vlasak, F. Rypacek, J. Drobnik, V. Saudek, Properties and reactivity of polysuccinimide, J. Polym. Sci. Part C-Polymer Symp. 64 (1979) 59-64.

[22] L.S. Yakimova, M.A. Ziganshin, V.A. Sidorov, V. V. Kovalev, E.A. Shokova, V.A. Tafeenko, V. V. Gorbatchuk, Molecular recognition of organic vapors by 
adamantylcalix[4]arene in QCM sensor using partial binding reversibility, J. Phys. Chem. B. 112 (2008) 15569-15575.

[23] A. V. Gerasimov, M.A. Ziganshin, A.E. Vandyukov, V.I. Kovalenko, V. V. Gorbatchuk, A.M. Caminade, J.P. Majoral, Specific vapor sorption properties of phosphoruscontaining dendrimers, J. Colloid Interface Sci. 360 (2011) 204-210.

[24] A. Dokoumetzidis, V. Papadopoulou, P. Macheras, Analysis of dissolution data using modified versions of Noyes-Whitney equation and the Weibull function, Pharm. Res. 23 (2006) $256-261$.

[25] S.M. Thombre, B.D. Sarwade, Synthesis and biodegradability of polyaspartic acid: A critical review, J. Macromol. Sci. Part A. 42 (2005) 1299-1315.

[26] M.E. Aulton, Aulton's Pharmaceutics: The Design and Manufacture of Medicines, 3th ed., Churchill Livingstone, Edinburgh, 2007.

[27] H.J. Park, B. Ramaraj, K.R. Yoon, Graft polymerization of p-dioxanone onto polyhydroxyethylaspartamide through ring-opening polymerization using organometallic and enzyme catalysts, Des. Monomers Polym. 16 (2013) 407-416.

[28] S.P. Hsu, I.M. Chu, Design of polyanionic nanocarriers based on modified poly(aspartic acid)s for oral administration: Synthesis and characterization, J. Polym. Res. 19 (2012) 9913.

[29] J. Feng, L. Gao, R. Wen, Y. Deng, X. Wu, S. Deng, Fluorescent polyaspartic acid with an enhanced inhibition performance against calcium phosphate, Desalination. 345 (2014) $72-$ 76.

[30] Y. Hiruta, T. Funatsu, M. Matsuura, J. Wang, E. Ayano, H. Kanazawa, pH/temperatureresponsive fluorescence polymer probe with $\mathrm{pH}$-controlled cellular uptake, Sensors Actuators B. Chem. 207 (2015) 724-731.

[31] C. Németh, B. Gyarmati, T. Abdullin, K. László, A. Szilágyi, Poly(aspartic acid) with 
adjustable pH-dependent solubility, Acta Biomater. 49 (2017) 486-494.

[32] M.E. Davis, S.H. Pun, N.C. Bellocq, T.M. Reineke, S.R. Popielarski, S. Mishra, J.D. Heidel, Self-assembling nucleic acid delivery vehicles via linear, water-soluble, cyclodextrincontaining polymers., Curr. Med. Chem. 11 (2004) 179-197.

[33] Y. Tang, J. Singh, Biodegradable and biocompatible thermosensitive polymer based injectable implant for controlled release of protein, Int. J. Pharm. 365 (2009) 34-43.

[34] D. Salakhieva, V. Shevchenko, C. Németh, B. Gyarmati, A. Szilágyi, T. Abdullin, Structure-biocompatibility and transfection activity relationships of cationic polyaspartamides with (dialkylamino)alkyl and alkyl or hydroxyalkyl side groups, Int. J. Pharm. 517 (2017), 234246.

[35] S. I. Kim, C.M. Son, Y.S. Jeon, J.H. Kim, Characterizations of novel poly(aspartic acid) derivatives conjugated with $\gamma$-amino butyric acid (GABA) as the bioactive molecule, Bull. Korean Chem. Soc. 30 (2009) 3025-3030. 